\title{
A complexidade da cultura amazônica e seu reflexo para a organização e representação da informação
}

\author{
Anderson Luiz Cardoso Rodrigues
}

\begin{abstract}
Resumo
Introdução: Explora e analisa o domínio 'cultura amazônica' no contexto da organização e representação da informação. Apresenta conceitos de cultura com o objetivo de embasar as reflexões sobre o domínio estudado. Método: 0 referencial teórico de apoio é centrado na Teoria da Classificação Facetada de Ranganathan e na Teoria dos Niveis Integrativos do Classification Research Group, como base teórico-metodológica para a elaboração de um modelo de estrutura classificatória. A seleção dos conceitos foi realizada tomando por base os termos resultantes de pesquisa oral de três localidades geográficas da Amazônia: as cidades de Bragança, Castanhal e o arquipélago do Marajó. Resultados: A análise das origens etimológicas das palavras indicou a influência das culturas estrangeiras dos continentes europeu, africano, asiático e americano na linguagem amazônica. Conclusões: A análise dos resultados revelou a viabilidade de se desenvolver uma metodologia de trabalho para delinear uma estrutura de classificação e de um conjunto de conceitos para representar o domínio 'cultura amazônica' nas suas raizes basilares como estrutura para a construção de sistemas de organização do conhecimento.
\end{abstract}

\section{Palavras-chave}

Conceitos. Análise de domínio. Cultura amazônica. Organização do conhecimento. Representação do conhecimento. Sistemas de classificação.

\section{Introdução}

Com o aumento da produção de informações houve uma preocupação por parte de vários profissionais sobre como organizá-las e recuperálas, pois não é necessário somente tornar a informação acessível, mas levá-la ao usuário certo e no momento adequado. Na busca da qualidade pela organização e recuperação da informação, atualmente se observa uma tendência na criação de instrumentos de recuperação da informação especializados, pois os conceitos podem ser trabalhados de forma minuciosa se comparados aos sistemas gerais, tais como os tesauros, as ontologias, as bases de dados etc.

Desse modo, esta pesquisa pretende discutir uma etapa inicial na construção de um sistema de organização do conhecimento: a seleção e levantamento conceitual no domínio "cultura amazônica”. O motivo pelo qual essa discussão vem à tona se deve a dificuldade encontrada quanto à precisão da seleção terminológica em um domínio complexo, como é o caso da cultura amazônica.

Conforme se pode observar nos apontamentos dos estudiosos da área, a definição de cultura amazônica tem vários olhares e abordagens possíveis e a clareza de seus limites é difusa. É difusa porque a própria definição do conceito assim o é, devido às inúmeras trocas culturais que ocorrem nas diferentes culturas e porque os seus limites tênues estão em movimento constante.

O objetivo da pesquisa foi evidenciar a problemática da seleção conceitual no domínio "cultura amazônica" e apontar alguns caminhos que levem a um melhor desenvolvimento na elaboração de sistemas de organização de conhecimento. Considerou-se que algumas teorias vêm em auxílio de tal propósito e a 
presente investigação busca uni-las à prática ao apresentar, no nível da categorização, uma estrutura de classificação do domínio.

Entendendo que o domínio "cultura amazônica" pode ser olhado a partir de várias abordagens que interagem entre si (interdisciplinaridade), são apresentadas as propostas da Teoria da Classificação Facetada e a Teoria dos Níveis Integrativos como referencial teórico de apoio para a organização e representação da informação. A Teoria de Ranganathan foi importante para o estudo pelo seu método facetado e a visão da policotomia ilimitada, que possibilita uma relação flexível entre conceitos na construção de um sistema de organização de conhecimento. A Teoria dos Níveis Integrativos pela abordagem do Classification Research Group (CRG) foi útil pela capacidade de representar os assuntos complexos de forma integrativa e interconectada e os conceitos em progressiva complexidade.

A importância de se conhecer um pouco a Amazônia, além da sua proclamada biodiversidade, as culturas híbridas de seus povos que compartilham uma raiz indígena, sobretudo no meio rural, é o legado adicional desta pesquisa. Em uma região ainda desconhecida em vários aspectos pela sociedade nacional e mundial, seu povo vem, desde tempos longínquos, construindo costumes, organizações sociais, mitos, maneiras de ver a vida, estados da alma, técnicas inovadoras, relações com a natureza e sustentabilidade ambiental o que a torna um patrimônio cultural da humanidade.

Somando-se a isso, a discussão da exploração mais refinada de domínios culturais no que tange a sua delimitação enquanto campo de conhecimento em linguagens documentárias, que são aspectos pouco tratados do ponto de vista da Ciência da Informação, esse estudo busca contribuir para análise sobre domínios dessa natureza.

Inicialmente, discute-se o conceito de cultura e cultura amazônica, ou seja, o domínio analisado e, em seguida, as teorias que embasaram o estudo: a Teoria da Classificação Facetada, e a Teoria dos Níveis Integrativos. Apresentadas as questões teóricas que norteiam a pesquisa são comentadas a metodologia e os resultados do trabalho acerca dos estudos etimológicos amazônicos e da categorização do domínio "cultura amazônica".

\section{O conceito complexo de cultura}

Cultura é um conceito ligado às Ciências Humanas e Sociais e, portanto, têm conceituações de várias escolas e pensamentos que foram evoluindo ao longo do tempo. Cultura é derivada da palavra latina culturae e segundo Eagleton (2005) é uma das duas ou três palavras mais complexas da nossa língua. Williams (2008, p. 10) afirma que o problema do estudo da sociologia da cultura está no próprio termo "cultura", que o considera um conceito "excepcionalmente complexo". Para Nunes (2004) o conceito de cultura é muito diversificado por natureza além de polêmico. Trata-se de "um desses conceitos quentes, em estado de fusão e reformulação, do qual é conveniente nos aproximarmos, como à busca de uma realidade ignorada, em movimento de câmera lenta" (NUNES, 2004, p. 6).

O domínio "cultura amazônica" na perspectiva da organização e representação do conhecimento apresenta complexidade em seu nível macro, uma vez que é parte integrante das Ciências Humanas. Para Langridge (1977) a organização de domínios do conhecimento nas Ciências Humanas e Sociais tem uma diferença profunda em relação às outras grandes áreas. As Ciências Exatas, por exemplo, tendem a ter um corpo mais harmônico de pensamento, enquanto que nas Ciências Humanas e Sociais há várias teorias e escolas. Para Maués (1999, p. 16) isso ocorre porque essas áreas manipulam objetos de análise radicalmente diferentes. Lévi-Strauss (1993) comenta que a diferença entre as Ciências Naturais e os estudos culturais se dá porque o observador é o próprio objeto de estudo e o homem, portanto, carece de método diferenciado de interpretação.

Como consequência dos vários olhares das Ciências Humanas e Sociais "[...] as fronteiras entre os vários estudos sociais são difíceis de estabelecer" (LANGRIDGE, 1977, p. 96). Gera- 
se, a partir dessa dificuldade, uma imprecisão conceitual que reflete na complexidade de se estabelecer a seleção e relações dos conceitos visando à construção de sistemas de organização do conhecimento baseados em domínios.

Para Loureiro (2001), a cultura é entendida como uma configuração intelectual, artística e moral de um povo ou, mais amplamente, de uma civilização, e que pode ser compreendida no processo de seu desenvolvimento histórico ou num período delimitado de sua história. Para Nunes (2004, p. 9) é a "soma de todas as criações que melhoram a condição material dos homens ou que expressam a vida intelectual e moral". A cultura reproduz o resultado do esforço de autoafirmação da espécie humana, que se desprendeu da condição da animalidade até atingir, passando pela selvageria e pela barbárie, os mais altos graus de desenvolvimento. Essa ideia, no entanto, é incompleta e foi corrigida e ampliada pelo conceito antropológico de cultura.

A cultura, como termo geral, significa a herança social total da humanidade. No conceito antropológico, a cultura é, para cada agrupamento humano, um conjunto de modos de proceder e pensar segundo estruturas normativas variáveis e particulares que sustentam diferentes padrões de pensamento e ação. A Antropologia e outras áreas de estudo ensinam a olhar e a compreender a variedade das culturas, indicando a síntese da criação do universo humano por meio de normas, indissociável da linguagem, técnicas, conhecimento, religião, valores éticos, estéticos e políticos existentes no conjunto de uma organização social determinada.

Aranha e Martins (1993) comentam que a palavra cultura tem vários significados, mas no campo da Antropologia a cultura é o que o homem produz ao construir sua existência, as práticas, as teorias, as instituições, os valores materiais e espirituais. Consideram que o contato do homem é intermediado através do símbolo e a cultura, portanto, é o conjunto de símbolos elaborados por um povo em um determinado tempo e lugar. Dada à infinita possibilidade de simbolizar, as culturas dos povos são consideradas como múltiplas e variadas.

\section{Cultura amazônica: sua complexidade e peculiaridade}

A cultura amazônica tem suas peculiaridades principalmente pela forte ligação com a etnia indígena $\mathrm{e}$, por conseguinte, tem sua raiz construída ao longo de milhares de anos. A complexidade desse domínio, além dessa raiz, se intensifica quando ocorrem os primeiros contatos dos índios com os europeus e os africanos e a evolução dessa troca cultural.

Quando fala do Brasil, Nunes (2004) comenta que o povo brasileiro é dotado de uma cultura própria, tem fisionomia distintiva e seu ethos peculiar encontra-se onde componentes de extração portuguesa se fundem àqueles caracteres primitivos, indígenas e negros.

A Amazônia, em grande parte, tem uma cultura intrinsecamente ligada às raízes indígenas. Porém com a mistura da cultura europeia e africana, aproximando-a e tornando-a indissociável da própria identidade brasileira. Veríssimo (1970) afirma que o Brasil é uma região onde as raças se mesclam, desaparecendo completamente os tipos puros e a região amazônica é um exemplo vivo desse fato. Maués (1999) afirma que a identidade regional amazônica é constituída por negros, índios, caboclos, mulatos, tapuios, mestiços, portugueses, paraoaras, amazônidas, brasileiros, católicos, protestantes, umbandistas, mineiros e uma infinidade de outras raças.

A cultura cabocla amazônica tornou-se a expressão popular das camadas populares das cidades paraenses. É uma cultura de fisionomia própria, com predomínio de elementos indígenas, mesclado a caracteres negros e europeus e cujo ator principal é o caboclo, resultante da miscigenação do índio com o branco, e cuja força cultural tem origem na forma de articulação com a natureza. 
Segundo Maués (1999) a diversidade indígena vêm se constituindo há milhares de anos - há aproximadamente 20 a $30 \mathrm{mil}$ anos antes da chegada do europeu. Foram chamados de índios em função do desconhecimento dos novos conquistadores em relação ao "novo mundo" que estavam descobrindo. No entanto, não se tratava de um mundo tão novo assim. Para se ter ideia da enorme população que existia antes do europeu chegar às terras brasileiras, o autor calcula que, no continente americano, havia aproximadamente cem milhões de índios quando da colonização, enquanto que no território brasileiro esse número chegava, aproximadamente, a cinco milhões de nativos. Atualmente, segundo o autor, acredita-se que existam apenas 400 mil índios e 200 etnias que ocupam o território brasileiro e 170 línguas (GAMBINI, 2000).

Muito do patrimônio cultural brasileiro foi dizimado, principalmente nas sociedades ágrafas. As línguas e os mitos, por exemplo, se acabam quando morre o último indivíduo da sociedade, pois há o fim da transmissão de geração para geração por meio da tradição oral. A população indígena já tinha consolidado uma grande diversidade sociocultural, dada sua organização social complexa, mitos e muitas línguas. Possuíam técnicas de caça e pesca próprias e diferentes maneiras de ver o mundo, conhecimento do manejo sustentado do ambiente, dos rituais, das crenças, do conhecimento da floresta e de muitos outros aspectos da cultura.

Os momentoshistóricos foramimportantes, sendo uma espécie de "divisor de águas" para mudanças das formas culturais na região amazônica. Foram impactos culturais que modificaram a Amazônia, trazendo, como qualquer contato interétnico, perdas e ganhos do ponto de vista cultural.

Mesmo sabendo da importância da biodiversidade amazônica, Maués (1999) afirma que há outra riqueza existente na Amazônia pouco comentada: a sociodiversidade. Ambas as diversidades tornam a relação, seleção e mapeamento conceitual de um sistema de organização do conhecimento especializado no domínio "cultura amazônica" uma tarefa difícil.
No entanto, Braudel (2004) propõe ideias fundamentais para se pensar esse aspecto, demonstrando a possibilidade do estabelecimento de limites em uma cultura híbrida. Comenta que a dificuldade de análise da atualidade se dá porque suas mudanças são muito lentas e morosas, portanto, só pode ser feita a partir de um olhar em um passado longínquo. Entretanto, afirma que nenhuma fronteira é fechada e que uma civilização está sempre recebendo e exportando bens culturais.

Para esse autor, nem todas as civilizações, devido aos seus padrões culturais construídos em raízes sólidas, estão prontas para assimilarem os bens da vida moderna indistintamente e recusam certas assimilações. O que explica porque conseguem salvaguardar suas originalidades. Essa rejeição é que forma sua verdade pessoal, pois lançou mão daquilo que a incomoda das terras limítrofes e estrangeiras. Isso acontece porque as civilizações apresentam o que Braudel (2004) chamou de estruturas culturais. Essas estruturas têm raízes profundas que duram muito tempo e oferecem traços distintivos e originais que conferem às civilizações sua fisionomia particular. Raramente permutam, pois são valores insubstituíveis que conduzem ao âmago de uma civilização.

Pode-se perceber que uma cultura ou civilização, embora partilhe incessantemente inúmeras trocas de bens culturais de toda ordem, ainda guardam em seu âmago suas peculiaridades originais, uma vez que recusam algumas trocas que afetem suas estruturas profundas. Sendo assim, em relação à cultura amazônica, é possível então entender que ela compõe certos traços culturais que lhe conferem uma fisionomia particular e tal fisionomia e originalidade compõe o que podemos chamar de "cultura amazônica". Desse modo, para pensar a seleção conceitual do domínio "cultura amazônica" deve se observar a originalidade dessa Região.

Segundo alguns estudiosos, a originalidade amazônica encontra-se em maior proporção no espaço classificado por Loureiro (2001) como espaço rural. Neste, a sociedade está mais ligada às raízes culturais por ter preservado a cultura 
tradicional construída há muito tempo pelo homem amazônico e, para Loureiro (2001), o capitalismo ainda não se apoderou totalmente nesse espaço da Amazônia.

\section{A Teoria da Classificação Facetada}

A chamada Teoria da Classificação Facetada foi desenvolvida por Shiyali R. Ranganathan na década de 1930. No Postulado das Categorias, Ranganathan (1967) preocupou-se com a concepção de categorias fundamentais. Esse postulado é um princípio normativo que serve para organizar um Universo/Domínio. As categorias fundamentais podem ser entendidas como: categorias as mais genéricas possíveis e possíveis de se manifestarem de diversas formas, capazes de hospedar todos os objetos da natureza até então conhecidos pelo homem e de classificálos de acordo com sua natureza conceitual, cada um numa somente numa categoria (CAMPOS; GOMES, 2008, p. 4-5).

As categorias fundamentais são o primeiro recorte feito no universo ou domínio do conhecimento. Para Ranganathan existem cinco categorias fundamentais que podem dividir todo e qualquer assunto, são elas Personalidade, Matéria, Energia, Espaço e Tempo (PMEST). Abaixo, apresenta-se a definição de cada categoria fundamental com base em Kumar (1981), Campos (2001a), Novo (2007), e o próprio Ranganathan (1967):

a) personalidade: a categoria Personalidade pode ser considerada, genericamente, como qualquer manifestação que tenha um caráter distintivo. Esta categoria é a base e o local de todas as outras categorias fundamentais;

b) matéria: a categoria fundamental matéria pode ser de dois tipos - material e propriedade;

c) energia: é uma manifestação de ação de um tipo ou outro;

d) espaço: também é definido no sentido usual, ou seja, o local de pertencimento de um objeto seja ele indivíduo, coisa, ideia, fenômeno ou outra entidade, tal como continente, países, estados;

e) tempo: essa categoria é vista como normalmente o ser humano a entende, tal como milênio, século, década, ano, e assim por diante.

Nesta pesquisa elaborou-se uma estrutura classificatória utilizando estas categorias fundamentais de Ranganathan. A estrutura foi produzida em seu nível básico, ou seja, no nível da categorização do domínio de conhecimento "cultura amazônica".

A categorização pode ser tomada como diretriz para se elaborar uma classificação. Para Campos e Gomes (2006), consiste em identificar as possíveis classes gerais (categorias) de conceitos que a área do conhecimento comporta. Permite uma análise conceitual de um domínio possibilitando um recorte amplo neste e permitindo um caminho inicial de divisão. Essa etapa estabelece as bases para seleção dos termos, nas fontes de onde eles são coletados. A categorização é descrito por Campos e Gomes (2008, p. 4) como:

\footnotetext{
um processo que requer pensar um domínio de forma dedutiva, ou seja, determinar as classes de maior abrangência dentro da temática escolhida. $\mathrm{Na}$ verdade, aplicar a categorização é analisar o domínio a partir de recortes conceituais que permitem determinar a identidade dos conceitos (categorias) que fazem parte desse domínio.
}

O primeiro passo do classificacionista para elaborar um esquema de classificação é mapear o Universo de Assuntos (CAMPOS, 2001a). Esta etapa tem como objetivo definir o nível de extensão que se dará o corte classificatório do Universo de Assuntos. O mapeamento consiste em se decidir a área de assunto que será baseada a organização dos conceitos e como esta área será classificada. Ranganathan (1967) afirma que o mapeamento conceitual é uma tarefa bastante complexa e exige profunda reflexão para que a classificação não seja marcada por um absurdo lógico.

Nesta pesquisa, procedeu-se o mapeamento conceitual pela categorização com base no 
PMEST e outras facetas de nível um pouco mais abaixo, sem entrar em níveis mais específicos e detalhados do interior do sistema de classificação. Pelo mapeamento conceitual se definiu a base teórica para seleção terminológica/conceitual das unidades conceituais do domínio "cultura amazônica”.

\section{A Teoria dos Níveis Integrativos}

A Teoria dos Níveis Integrativos não tem uma origem precisa, mas pode-se dizer que a raiz dessa concepção pode ser encontrada nos cinco níveis de Aristóteles. No século XIX, a teoria recebeu impulso com a filosofia positivista de Augusto Comte, que acreditava que a classificação das ciências existia na ordem do mais simples para o mais complexo e as mais complexas dependiam das mais abstratas (SPITERI, 1995).

Para os estudos da teoria da classificação, o Classification Research Group (CRG) adotou como base a teoria de Ranganathan e a Teoria dos Níveis Integrativos. O CRG, sediado em Londres, foi fundado em 1952 e tem realizado contribuições significativas para a teoria da classificação.

O CRG opôs-se aos sistemas tradicionais, pelo entendimento de que o universo do conhecimento não poderia ser definido como finito, e ainda subdividido até os conceitos individuais. Desse modo, o CRG, tomando como base a Teoria dos Níveis Integrativos, sugeriu uma abordagem bottom-up, em contraposição a abordagem topdown dos sistemas tradicionais. Seus especialistas questionaram e sugeriram que, ao invés de "quebrar" o universo do conhecimento em classes e analisá-las até se chegar a conceitos individuais, os conceitos formassem assuntos.

O CRG interpretou a Teoria dos Níveis Integrativos da seguinte forma: $\mathrm{o}$ mundo das coisas se desenvolve do simples para o complexo pelo acúmulo das propriedades novas e divergentes. De coisas simples evoluem coisas complexas e de coisas complexas evoluem coisas mais complexas (NOVO, 2007). Assim, para a
Teoria dos Níveis Integrativos é considerado a evolução do desenvolvimento de entidades com base na estrutura de seus componentes internos. Para Schreiner (1979), o conceito de níveis integrativos de organização é a descrição geral da evolução da matéria por meio das sucessivas e mais altas ordens de complexidade e integração. O desenvolvimento da matéria é visto desde as mudanças cosmológicas que resultam na formação da Terra até as mudanças sociais complexas de uma sociedade por um processo contínuo, passando por diferentes níveis de organização, como o físico, o químico, o biológico e o sociológico.

Cada entidade preserva sua integridade nas relações com suas partes. Como a entidade evolui do simples para o mais complexo, pela acumulação de propriedades ou influências do ambiente, ocorrem agregações de entidades ou propriedades e se forma um novo todo mais complexo. A nova entidade tem propriedades próprias e se comporta de maneira nova. Cada entidade inteira é maior que a soma das partes e, se uma das relações estiver quebrada, a entidade perde sua identidade (FOSKETT, 1978).

Nessa perspectiva, a noção de "integração" é inseparável da noção de "totalidade", porque o todo é composto de uma série de elementos integrados. Usando o exemplo de Foskett (1978), uma bicicleta é um amontoado de peças (aço, borracha, alumínio etc.), mas quando suas partes são colocadas juntas a partir de um determinado conjunto exato de relações, surge uma nova entidade. Essa nova entidade, a partir do conjunto das partes e suas relações, fazem a bicicleta andar e se locomover adequadamente.

A inter-relação entre os elementos do sistema cultural é inerente ao campo da cultura. Existe um todo (cultura amazônica) que se relaciona com suas partes (fauna, flora, religião, mitologia, formas de pensar a vida e a natureza etc.) e a soma de suas partes formam a cultura amazônica.

Os vários olhares possíveis do domínio "cultura amazônica" refletem-se na construção do sistema de organização do conhecimento. 
Para Novo (2010), os estudiosos preocupados com o problema da classificação de domínios de conhecimento são unânimes em afirmar a existência de vários pontos de vistas no ato classificatório.

A cultura amazônica pode ser olhada pelo ponto de vista da modernidade, pela dinâmica de suas cidades, ou pelo ponto de vista de suas raízes mais profundas criadas há muito tempo pelos nativos indígenas, pela dinâmica menos frenética dos municípios do interior paraense. Também pode ser examinada por dois espaços culturais como sugerido por Loureiro (2001): o espaço rural e o espaço urbano amazônico. Os resultados revelam que o espaço mais autêntico de preservação da identidade amazônica foi o espaço rural.

A cultura amazônica, como qualquer conhecimento humano, é dinâmica e vem se transformando ao longo de sua história. Os valores culturais obtidos pela troca com outras civilizações se agregam e vão modificando o domínio ao ponto de, em alguns casos, a mudança ser tão brusca que implica em certa perda de identidade cultural amazônica. Assim, diante desses momentos históricos violentos de grande impacto cultural uma nova identidade começa a formar-se, relativamente diferente da anterior.

Ao referir-se à cultura amazônica, Loureiro (2001) afirma que ela é dinâmica, original e criativa, haja visto que revela, interpreta e cria sua própria realidade. O contato intercultural acabou por dinamizá-la e propiciar um movimento intenso, ao mesmo tempo em que essa mistura proporcionou uma heterogeneidade difícil de separar as partes. No meio rural esse movimento parece ocorrer com menor velocidade e a homogeneidade é maior.

Para Laraia (2002) nenhuma cultura é estática, mesmo nas pequenas sociedades, embora aparente ser. $\mathrm{O}$ autor utiliza como exemplo um ritual indígena para demonstrar o dinamismo de uma sociedade denominada simples. Quanto mais isolada é uma sociedade mais será lenta sua mudança. Mesmo assim, até nas sociedades indígenas isoladas ocorrem mudanças, embora tenham um ritmo menos acelerados que uma sociedade complexa. Segundo Loureiro (2001) a cultura amazônica, em especial o seu meio rural, como uma sociedade denominada simples, as suas mudanças internas acontecem com menor velocidade se comparadas às sociedades mais complexas, como as grandes cidades. Como não é uma sociedade isolada, muitos momentos históricos marcantes do ponto de vista cultural, decorrentes dos contatos com outras sociedades, impulsionaram um movimento mais brusco na cultura amazônica. Desses contatos avassaladores decorrem a complexidade da delimitação do domínio e da seleção e levantamento conceitual. É necessário observar o movimento dinâmico próprio da cultura amazônica na construção de um tesauro ou de um sistema de organização do conhecimento. É importante analisar como ocorreu a progressão histórica da região para o entendimento da sua transformação e como essa transformação pode ajudar na qualidade da seleção e levantamento conceitual. Importa também identificar quais fatores levaram a um dado elemento que não era parte do sistema cultural "cultura amazônica" e começou a ser parte integrante do mesmo, ou seja, como se fundiu e se agregou a cultura amazônica.

Como afirma Novo (2007, p. 111), a Teoria dos Níveis Integrativos, como o próprio nome já diz, é uma teoria e não um método classificatório per se, pois "[a]presenta princípios e não uma dada forma do fazer." No contexto desta investigação permitiu olhar mais claramente um domínio complexo, como o da cultura amazônica, nas suas questões fundamentais a partir de diferentes perspectivas conceituais.

\section{Metodologia}

A pesquisa teve dois momentos distintos para alcançar seu objetivo: primeiramente, visou-se discutir e demonstrar a complexidade da seleção conceitual do domínio de conhecimento "cultura amazônica" e, em um segundo momento, buscou-se apresentar um modelo-diretriz de representação. No primeiro momento, estudouse o conceito de cultura e cultura amazônica e se 
efetivou uma análise das origens etimológicas das palavras amazônicas, de forma a compreender e analisar o domínio em sua complexidade; e, no segundo momento, elaborou-se um modelo de estrutura de classificação no seu nível básico como resultado/produto dos estudos teóricos.

O estudo sobre o conceito de cultura, destacado anteriormente, levou o pesquisador a pensar a cultura amazônica tanto como parte de um todo como também enquanto elemento individualizado e ímpar. No sentido de tentar mostrar como toda cultura é complexa foram estudados autores que discutiram o conceito ampla e historicamente, apresentando sua evolução ao longo do tempo.

A análise das origens etimológicas dos termos relacionados à cultura amazônica teve o intuito de revelar a complexidade do domínio pela diversidade cultural e o entendimento dos conceitos. Esse estudo também auxiliou na construção do modelo de classificação apresentado na pesquisa.

$\mathrm{Na}$ elaboração da estrutura classificatória foi empregado o método da categorização do domínio "cultura amazônica". O exercício da categorização torna claro o domínio e estabelece as bases para a seleção terminológica nas fontes onde são coletadas. Vale lembrar que a estrutura classificatória mais detalhada pode ser observada em Rodrigues (2011).

A categorização foi feita pelas categorias fundamentais/PMEST (bottom-up) de Ranganathan (1967) e, no interior das categorias, efetivou-se o caminho inverso (top-down). Foram observadas as potenciais unidades conceituais de Oliveira (2005a, 2005b, 2010) para serem formadas as facetas e classes. No interior das categorias fundamentais foram usados alguns princípios e abordagens da Teoria dos Níveis Integrativos, do CRG.

Para a criação das facetas e classes no interior das categorias fundamentais tomamos como base as estruturas classificatórias da pesquisa de Rodrigues (2005), do Tesauro de Cultura Popular e Folclore (TESAURO..., [2010]) e da Classificação Decimal Universal (CDU) (UNIVERSAL..., 2009).

O trabalho de Rodrigues (2005) teve como objetivo elaborar uma estrutura de classificação, visando a elaboração de um tesauro, com os termos culturais das narrativas orais populares do Marajó do projeto IFNOPAP ${ }^{1}$, do Centro de Letras da Universidade Federal do Pará e da obra "Chove nos Campos de Cachoeira", de Dalcídio Jurandir. O Tesauro de Cultura Popular e Folclore serviu de base devido a sua estrutura de classificação e o seu domínio, o qual se aproxima do domínio analisado nesta pesquisa. A CDU forneceu uma visão geral de como podem ser classificadas todas as áreas do conhecimento, tomando-se como exemplo algumas classes e relações hierárquicas presentes nesta Classificação como apoio para pensar a organização do domínio "cultura amazônica”.

Nesta pesquisa, entretanto, se entendeu que o hibridismo entre os métodos e abordagens seria mais adequado para a análise do domínio "cultura amazônica" no âmbito da organização e representação de informação para sistemas de organização do conhecimento. Foram definidos os seguintes passos metodológicos. Quanto ao método da garantia literária, ou seja, o método indutivo, comentado por Batista (2004), foi tomado como base os termos culturais coletados por Oliveira (2005a, 2005b, 2010) que apresentam as terminologias culturais das narrativas orais populares coletadas por pesquisadores do projeto IFNOPAP, do Centro de Letras e Artes da Universidade Federal do Pará, nos municípios paraenses de Bragança, Castanhal e arquipélago do Marajó. Os termos serviram de base para formar as facetas e classes na elaboração da estrutura classificatória e para a análise das etimologias. Os 1109 termos analisados possibilitaram identificar as facetas possíveis de serem criadas na composição do universo terminológico cultural amazônico.

\footnotetext{
${ }^{1}$ O Imaginário nas Formas Narrativas Orais Populares da Amazônia Paraense.
} 
A coleta dos termos foi feita pelo projeto RESNAPAP $^{2}$, da Universidade Federal do Pará, onde coletaram sua terminologia nas narrativas orais do projeto IFNOPAP. A partir do olhar bottom-up foi elaborada a estrutura classificatória no interior das categorias. Com base nessas unidades formamos uma estrutura em seu nível básico, embora não se tenham apresentado os conceitos de níveis mais baixos.

O método dedutivo também foi utilizado quando se usou as categorias fundamentais sugeridas por Ranganathan, Personalidade, Matéria, Energia, Espaço e Tempo, como base para o primeiro recorte no domínio "cultura amazônica". Tendo sido utilizadas as duas teorias, a de Ranganathan e a do CRG na construção de um possível modelo de estrutura classificatória de nível básico, o hibridismo metodológico mostrou-se um caminho natural. No primeiro nível, representado pelas categorias fundamentais, utilizou-se o método dedutivo usado por Ranganathan em sua Teoria da Classificação Facetada e, no interior das categorias fundamentais, a base seguida foi a Teoria dos Níveis Integrativos, enquanto método indutivo indicado pelo CRG. A posição das facetas principais (um nível abaixo das categorias) teve como base o método indutivo para agregar as categorias fundamentais escolhidas para recortar o domínio estudado.

Os procedimentos metodológicos utilizados na pesquisa foram considerados adequados para o desenvolvimento do estudo. A complexidade do domínio "cultura amazônica" demonstrou-se na dificuldade de seleção e levantamento conceitual e no modelo de recorte possível para a estrutura classificatória, a partir do estudo teórico realizado.

\section{Análise e interpretação dos resultados}

São apresentados, a seguir, os resultados da pesquisa sobre as etimologias e a categorização da estrutura de classificação do domínio "cultura amazônica”. Para conhecer o domínio e estruturálo, o esclarecimento sobre os paradigmas que envolvem o conceito cultura amazônica foram discutidos e dissecados na dissertação de mestrado de Rodrigues (2011).

\section{Etimologia da linguagem regional}

Em relação aos termos coletados na cidade de Bragança obteve-se um total de 216 termos. Quanto à cidade de Castanhal os termos coletados com base em Oliveira (2005a) somaram 347. Os termos coletados com base em Oliveira (2010) e referentes ao arquipélago Marajó somaram um total de 272. A soma de todas as regiões totalizou 831 termos, conforme pode ser visualizado na Tabela 1.

Éinteressante destacar que houve um sincronismo na proporção e predominância das etimologias

Tabela 1 - Total de termos das origens etimológicas das cidades de Bragança, Castanhal, e de cinco municípios do arquipélago do Marajó

\begin{tabular}{|c|c|c|}
\hline \multirow{2}{*}{ Origem etimológica } & \multicolumn{2}{|c|}{ Bragança, Castanhal e Marajó } \\
\hline & Termos & Percentual $(\%)$ \\
\hline Total & 831 & 100 \\
\hline Latim & 517 & 62,2 \\
\hline Tupi & 111 & 13,3 \\
\hline Espanhol & 50 & 6,0 \\
\hline Francês & 46 & 5,5 \\
\hline Grego & 16 & 1,9 \\
\hline Onomatopaica & 16 & 1,9 \\
\hline Gótico & 15 & 1,8 \\
\hline Arabe & 12 & 1,4 \\
\hline Italiano & 12 & 1,4 \\
\hline Quimbundo & 7 & 0,8 \\
\hline Germânica & 5 & 0,6 \\
\hline Malaio & 5 & 0,6 \\
\hline Castelhano & 3 & 0,3 \\
\hline Catalão & 3 & 0,3 \\
\hline Celta & 2 & 0,2 \\
\hline Portuguesa & 2 & 0,2 \\
\hline Quicongo & 2 & 0,2 \\
\hline Tâmul/Malaiala & 2 & 0,2 \\
\hline Africano & 1 & 0,1 \\
\hline Chinês & 1 & 0,1 \\
\hline Inglês & 1 & 0,1 \\
\hline loruba & 1 & 0,1 \\
\hline Tupi-guarani & 1 & 0,1 \\
\hline
\end{tabular}

Fonte: 0 autor.

\footnotetext{
${ }^{2}$ A Representação Simbólica das Narrativas Populares da Amazônia Paraense.
} 
em todas as regiões analisadas. O Latim sendo predominante, seguido do Tupi e depois do Espanhol e do Francês. Por vezes, uma relativa representatividade do Árabe, do Gótico e do Italiano. O Africano aparece em todas as regiões, mas sempre com expressividade reduzida.

Analisando-se todos os termos observados quanto às origens etimológicas percebe-se uma forte diversidade de línguas de origens estrangeiras na região. Aparentemente esse fato não deveria ocorrer de forma tão acentuada, dado que as cidades incluídas no universo de pesquisa estão localizadas no interior paraense. O contato com outras culturas não se deu de uma forma muito intensa dada a dificuldade de acesso, mas provavelmente ocorreu no período colonial, com exceção de Castanhal, que configura-se uma cidade de maior porte.

Tendo em vista que a pesquisa objetivou discutir a questão da seleção e levantamento de conceitos para uma estrutura de organização do conhecimento no domínio "cultura amazônica", o estudo das origens etimológicas teve dois propósitos: o de conhecer o domínio e entender as fronteiras do mesmo e o de evidenciar a complexidade do domínio. A diversidade linguística implica e ratifica a complexidade do domínio "cultura amazônica", sobretudo quanto ao aspecto da seleção e levantamento conceitual, mesmo no espaço rural que, teoricamente, tem menor troca cultural.

\section{Categorização do domínio "Cultura Amazônica"}

A categorização do domínio "cultura amazônica" foi composta a partir das unidades conceituais dos termos culturais coletados por Oliveira (2005a, 2005b, 2010). Foram utilizadas as categorias fundamentais de Ranganathan como recorte temático inicial, a saber: Personalidade $(\mathrm{P})$, Matéria (M), Energia (E), Espaço (S - space em inglês) e Tempo (T). No interior da estrutura classificatória foram analisados e utilizados os cânones de Ranganathan e os elementos sugeridos pela Teoria dos Níveis Integrativos.
A seguir, apresentaremos a discussão e análise sobre o modelo de organização do conhecimento no domínio "cultura amazônica".

A Categoria Personalidade, segundo Costa e Ramos (2008), é aquela que tem como característica distinguir o assunto ou o domínio de conhecimento em questão. Nesta pesquisa, foram englobados em Personalidade a Linguagem, a Mitologia e a Religião da população amazônica. Essas facetas, elementos fundamentais do domínio "cultura amazônica", constituem o cerne da identidade cultural amazônica.

A Linguagem, para Lévi-Strauss (1993), é um processo cultural e um produto da cultura: não existiria cultura se $\mathrm{o}$ homem não tivesse a possibilidade de desenvolver um sistema articulado de comunicação oral. A cultura amazônica é formada por um híbrido linguístico entre a língua indígena, a europeia e a africana, que compõe e demonstra a característica própria da região como um elemento de formação da identidade amazônica. A Mitologia é uma tradição antiga que revela as estórias de encantamento da região e que representam o inconsciente coletivo amazônico e, neste particular, a Amazônia vive em constante devaneio favorecido pelo ambiente cotidiano envolvido por uma atmosfera mitológica. A Religião no domínio "cultura amazônica" revela a forma de pensar do homem amazônico e a relação de ligação com a divindade, juntamente com seus elementos mitológicos, de encantarias e de certo devaneios formam um aspecto imprescindível de sua identidade cultural. O conjunto dessas três facetas e a relação forte do habitante da Amazônia Paraense com a natureza forma os pilares da identidade da região.

Em relação à categoria Matéria foram seguidas as recomendações de Kumar (1981). Essa categoria é composta pelo material e pelas suas propriedades e foram inseridos os produtos típicos dos habitantes amazônicos. A Categoria Matéria foi composta por quatro facetas: Fauna, Flora, Artefatos e Meios de Transporte.

Uma parte das facetas criadas na categoria Matéria está relacionada aos produtos oriundos 
da natureza da região, como as diversificadas faunas e a flora amazônica. Outra parte está ligada aos meios de transporte usados pelos habitantes amazônicos, como exemplo, o burro e o cavalo, muito usados nos interiores paraenses com a função de locomover pessoas e transportar mercadorias e aos artefatos artísticos, religiosos, domésticos e os instrumentos de trabalho amazônicos. As facetas criadas se encaixaram adequadamente a categoria matéria.

A Categoria Energia, como é definida por Ranganathan, está ligada aos conceitos relativos à ação. Desse modo, formaram-se três facetas relacionadas a atividades: Atividade de Cura, Atividade Econômica e Atividade Artística. No universo cultural amazônico, a Energia pode ser pensada em qualquer tipo de atividade cotidiana (ação) desenvolvida pelos habitantes locais, tais como a agricultura, a caça, o garimpo, a pecuária, o comércio, a culinária, o extrativismo, a pesca, a arte e a medicina.

A atividade de Cura é relacionada a práticas de cura adquiridas pelos conhecimentos empíricos tradicionais dos índios, como a medicina popular, o curandeirismo e a pajelança. A atividade Econômica são as atividades produtivas do cotidiano do homem amazônida utilizadas para seu próprio sustento ou para relações de trocas comerciais, onde são usados os elementos da fauna e da flora regional. A faceta atividade Artística foi composta por classes ligadas as artes, como a Arquitetura, o Artesanato, a Cerâmica, o Cinema e o Teatro, a Dança, o Desporto, a Música e a Pintura, além das festividades regionais típica da região amazônica, como por exemplo, o Círio de Nazaré, o Sairé, entre tantas outras.

A Categoria Espaço formou duas facetas demonstrando os espaços que caracterizam a região amazônica: o espaço geográfico e o espaço cultural. No espaço geográfico foram representados os principais elementos que compõem a região amazônica que tem influência direta na cultura local e no comportamento de seus habitantes. A categoria Espaço Cultural foi criada a partir da abordagem de Loureiro
(2001) e composta pelo espaço urbano e o rural, exemplificados a seguir:

a) espaço rural: compreende os municípios, vilarejos, vilas dos interiores da Amazônia paraense onde a urbanização e o desenvolvimento industrial e tecnológico ocorrem em menores proporções. As trocas simbólicas e a estrutura de ensino são proporcionalmente menores se comparados ao espaço urbano. A área rural é a que mais representa a identidade amazônica, pois tem uma ligação forte com as raízes tradicionais, prevalecendo a manutenção cultural através da tradição oral passada de geração para geração pelos habitantes mais antigos da região. É mais propício um ambiente mitológico pela forte relação com a natureza (animismo); e

b) espaço urbano: neste espaço as trocas simbólicas com outras culturas são mais intensas. Por ser um espaço onde há maior mistura cultural e recebe influências através do próprio ensino, dos meios de comunicação e das Tecnologias de Informação e Comunicação (TICs), a autenticidade, na visão de alguns estudiosos, em relação à identidade é menor.

Os espaços amazônicos, principalmente em relação ao geográfico, são muito representativos da região, em decorrência da enorme extensão territorial da própria floresta. Os espaços de trabalho e lazer dos habitantes do meio rural estão muito ligados à natureza, à água, como por exemplo, os rios e os igarapés.

A Categoria Tempo formou duas facetas: Tempo Histórico e Tempo Relativo à Natureza. Os renques decorrentes representam as noções temporais dos habitantes amazônicos.

O Tempo Histórico engloba os principais acontecimentos que ocorreram ao longo da história da Amazônia. Entre esses acontecimentos destacam-se os contatos interétnicos que foram mais significativos do ponto de vista cultural e que repercutiram em intensivos impactos culturais, colaborando para a formação da identidade da sociedade amazônida. Seguem alguns exemplos:

a) "Descobrimento do Brasil", em 22 de abril de 1500; 
b) "Catequese dos jesuítas europeus" no século XVI;

c) "Ciclo da Borracha", final do século XIX;

d) "Introdução de políticas públicas impostas pelo Governo Federal", na década de 60 do século XX;

e) "A globalização", no final do século XX até a atualidade; e

f) "Advento dos meios de comunicação e TICs", meados do século XIX até a atualidade.

O Tempo Relativo à Natureza é a noção temporal principalmente dos habitantes que vivem nos interiores paraenses, ou seja, no espaço rural amazônico. A noção de tempo está muito ligada aos fenômenos naturais. O sol, a lua, a maré, a chuva são exemplos de referentes temporais dos habitantes amazônidas.

É válido destacar que esse padrão temporal relativo à natureza foi a noção utilizada pelas civilizações da antiguidade. Essa faceta corrobora com a teoria de Loureiro (2001) em que a Amazônia vive um eterno começo e a lógica racional filosófica ainda não é muito presente. Segundo Waldman (1995) esse formato de tempo é uma forma particular de relação homem-tempo- natureza das sociedades pré-modernas, não ocidentais, não-brancas e não-burguesas onde o tempo é assimilado em sua pureza primitiva, em sua "essencialidade mais profunda inteligível por intuição” (WALDMAN, 1995, p. 1).

As facetas criadas para a estrutura de classificação (Figura 1) que foi elaborada na pesquisa objetivou contemplar os principais elementos culturais da identidade amazônica. Desse modo, foram utilizados elementos do espaço urbano e do espaço rural amazônico. A seguir segue a análise geral sobre a estrutura de classificação.

\section{Análise geral da estrutura de classificação}

Além de serem usadas as categorias propostas pelo CRG, a Teoria dos Níveis Integrativos auxiliou o pesquisador a pensar o domínio "cultura amazônica" de uma forma integrativa e interconectada. $\mathrm{O}$ pensar integrativo é peculiar do conceito cultura e sistema cultural, pois todos os elementos culturais, desde os homens até os produtos criados e usados por eles, assim como a natureza, são dependentes do contexto cultural. O homem, por exemplo, tem relação com a natureza, porque é dela que extrai sua alimentação, trabalho, lazer etc., e, por sua

Figura 1 - Categorização do domínio "cultura amazônica"

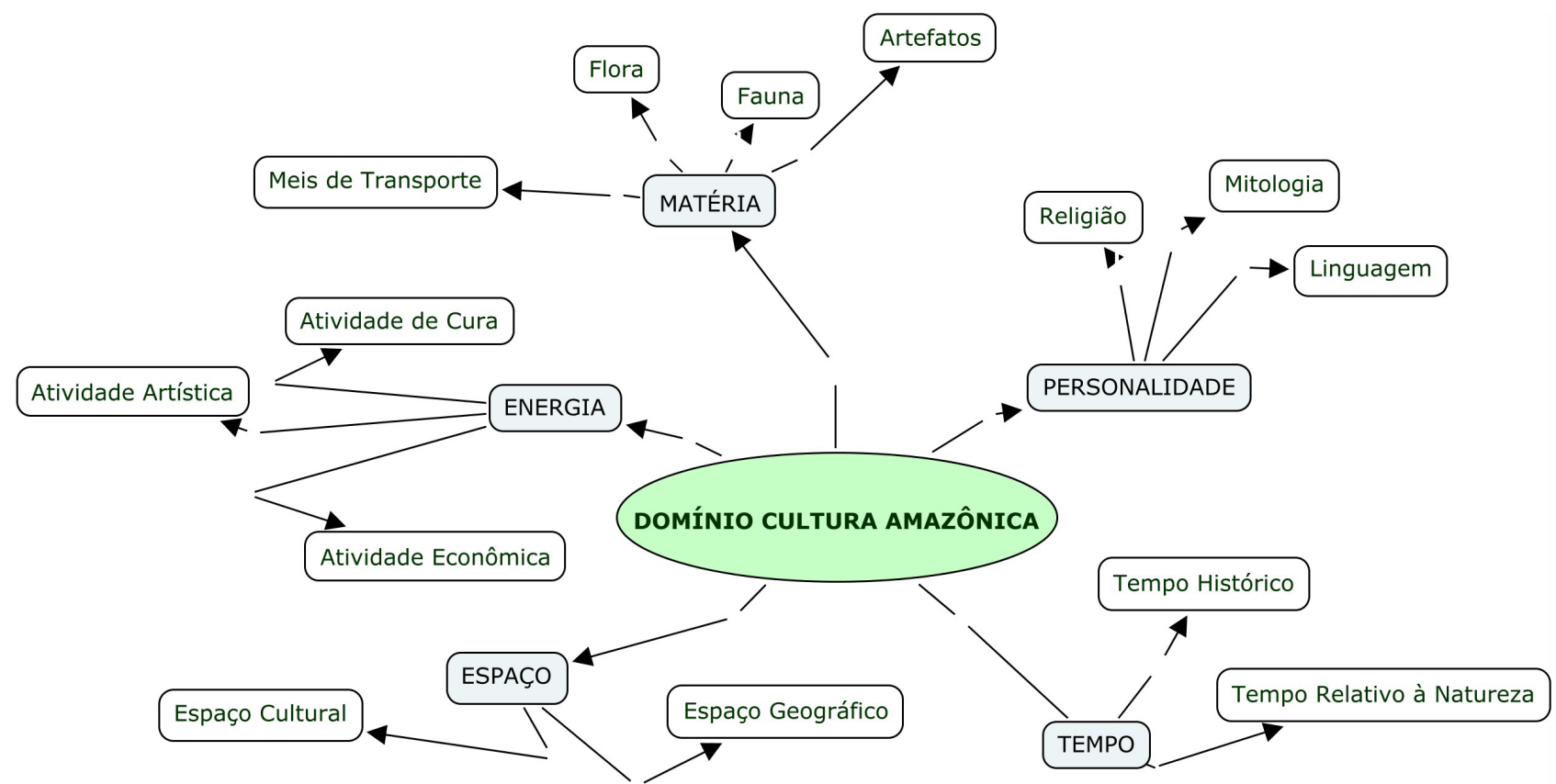


vez, cria e utiliza os meios de transportes para se locomover mais rapidamente para lugares mais distantes. Necessita do tempo, padrão que convencionou para se situar melhor no espaço, assim como seu tempo também depende da natureza, tal como os conceitos/elementos de dia e noite, maré cheia e maré baixa etc. A sua alimentação diária e seu comércio estão ligados aos produtos retirados da natureza e aos meios de transporte para poder comprar e vender esses produtos e assim por diante. Percebe-se que entre um elemento e outro há um encadeamento e, dependendo do referencial, é possível haver uma ligação mais forte ou não.

\section{Considerações finais}

A pesquisa teve como objetivo mostrar a complexidade do domínio "cultura amazônica" e apresentar uma categorização como diretriz de organização do conhecimento acerca do domínio baseado nas Teorias da Classificação Facetada, de Ranganathan e na Teoria dos Níveis Integrativos, do Classification Research Group.

As duas teorias foram fundamentais $\mathrm{e}$ complementares para tratar esse domínio complexo. A Teoria de Ranganathan foi importante para entender o fluxo do conhecimento e o dinamismo do mesmo. O sistema facetado sugerido se apresentou como uma maneira de contornar tal dinamismo e possibilitar a hospitalidade contínua num dado sistema de organização do conhecimento.

Como o próprio nome já diz, a Teoria dos Níveis Integrativos é uma teoria e não uma fórmula de como fazer. Portanto, este aporte ajudou a pensar o domínio, de uma forma interconectada e integrada revelando que os elementos do sistema cultural amazônico estão todos relacionados e amparados por um padrão cultural comum, como alegam os antropólogos e sociólogos.

O pensar sistêmico e integrado da organização do conhecimento na Teoria dos Níveis Integrativos, que pode ser observado nos princípios de Feibleman (1954) e Wilson (2002), é um pensamento adequado ao domínio de conhecimento "cultura amazônica". Na Teoria dos Níveis Integrativos os conceitos não podem ser compreendidos isoladamente, mas de forma interconectada dependente de processos cíclicos. Como o foco da teoria é a interconectividade, ela ajuda a lidar com estruturas complexas dos conceitos, as quais podem ser usadas em qualquer área.

Ainda em relação à Teoria dos Níveis Integrativos, na abordagem bottom-up sugerida pelo CRG, foram tomados como base os termos culturais coletados por Oliveira (2005a, 2005b, 2010), ou seja, apropriaram-se conceitos individuais para formar as facetas e as classes, tal como já realizado por Rodrigues (2005). A ideia dos conceitos individuais formarem as classes é uma oposição a abordagem top-down dos sistemas de classificações tradicionais, considerada pelo próprio $\mathrm{CRG}$ menos eficaz para assuntos complexos.

Pelos resultados apresentados foi mostrada a complexidade do domínio através do posicionamento dos especialistas sobre a definição do conceito de cultura e pela análise das origens etimológicas da linguagem regional amazônica. $\mathrm{Na}$ apresentação de um modelo que poderá servir de diretriz para construção de sistemas de organização e representação do conhecimento no domínio "cultura amazônica", elaborou-se uma estrutura classificatória a partir do método de categorização e das teorias de Ranganathan e do CRG.

A complexidade do domínio "cultura amazônica" encontra-se no próprio conceito de cultura. Os contatos interétnicos sofridos na região foi o ponto de partida para mostrar a sua complexidade, pois as influências de outras culturas sempre abalam a estrutura vigente de uma sociedade. Conhecer o que compõe essa cultura é uma tarefa árdua porque, a partir dos contatos, são agregados valores e produtos ao conjunto do sistema cultural amazônico. Os impactos culturais sofridos pela região ao longo de sua história, sobretudo, os de grande importância, são olhares importantes. Os costumes, hábitos e a 
língua nativa são modificados, produzindo uma fusão de elementos conceituais de uma possível estrutura classificatória nesse domínio.

Mesmo com as modificações decorrentes dos contatos interétnicos em momentos importantes da história de uma sociedade, assim como as modificações internas que ocorrem a partir de uma invenção ou de algum acontecimento importante, a estrutura cultural se altera muito pouco e lentamente porque é, consciente e inconscientemente, o alicerce daquela sociedade, segundo Braudel (2004). Sabendo dessa estrutura, o domínio cultural deve focar essas originalidades e raízes profundas e quase inalteráveis, além de buscar o que depois foi se agregando junto a essa estrutura sólida.

Os resultados revelados pela análise etimológica dos termos culturais amazônicos reiterou a complexidade do domínio cultura. A partir das origens etimológicas, foi mostrada a influência das línguas de várias partes do mundo na língua amazônica. A pesquisa etimológica demonstrou que a cultura amazônica é tomada por um hibridismo cultural e uma mestiçagem muito forte. Observa-se que as etimologias que ocorreram na terminologia amazônica são reflexos históricos das migrações de diversos povos, consequência de políticas internacionais inicialmente e depois pelas políticas nacionais na região amazônica como na Era da Borracha, no Programa de Integração Nacional (PIN), nos anos 1970, e nos grandes projetos que ocorreram na Amazônia.

É importante destacar que o propósito de um sistema de organização do conhecimento depende do interesse e perfil da comunidade a que se destina. Toda construção pode ser arranjada conforme a necessidade do uso de seus usuários. Um recorte no espaço rural ou no espaço urbano, utilizar uma teoria ou outra, depende do propósito quando se constrói o sistema.

Porfim, entendendoacomplexidadeeimportância do estudo proposto conclui-se, utilizando-se as palavras de Saracevic (1999) relativas à origem da Ciência da Informação, o qual afirma que "não somos estudiosos de assuntos, mas estudantes de problemas". São os problemas que impulsionam as pesquisas científicas, em uma tentativa de melhorar a qualidade de vida e a condição social humana.

\section{Referências}

ARANHA, M. L. de A. MARTINS, M. H. P. Filosofando: introdução à Filosofia. 2 ed. São Paulo: Moderna, 1993.

BATISTA, G. H. R. Rede de conceitos. Perspectivas em Ciência da Informação, v.9, n.1, p.6-17, jan./jun. 2004. Disponível em: $<$ http://portaldeperiodicos.eci.ufmg. br/index.php/pci/article/view/347/156>. Acesso em: 12 de nov. 2010

BRAUDEL, F. Gramática das civilizações. 3 ed. São Paulo: Martins Fontes, 2004.

CAMPOS, M. L. de A. A organização de unidades de conhecimento em hiperdocumentos: o modelo conceitual com um espaço comunicacional para realização da autoria. 2001. $171 \mathrm{f}$. Tese (Doutorado em Ciência da Informação). Escola de Comunicação da Universidade Federal do Rio de Janeiro, Rio de Janeiro, 2001a.

CAMPOS, M. L. de A.; GOMES, H. E. Metodologia de elaboração de tesauro conceitual: a categorização como princípio norteador. Perspectivas em Ciência da Informação, v. 11, n. 3, p. 348-359, 2006. Disponível em: < http://portaldeperiodicos.eci.ufmg.br/index. php/pci/article/view/273/66>. Acesso em: 5 set. 2009.

CAMPOS, M. L. de A.; GOMES, H. E. Taxonomia e classificação: o princípio de categorização. DataGramaZero - Revista de Ciência da Informação, v. 9, n. 4, ago. 2008. Disponível em: <http://www. datagramazero.org.br/ago08/Art_01.htm >. Acesso em: 12 jan. 2010.

COSTA, F. C. da; RAMOS, L. e B. Análise facetada: em busca de uma classificação para o teatro. Ponto de Acesso, v. 2, n. 3, p. 30-42, dez. 2008. Disponível em: <http://www.portalseer.ufba.br/index.php/revistaici/ article/viewArticle/3215>. Acesso em: 22 dez. 2010.

EAGLETON, T. A idéia de cultura. São Paulo: UNESP, 2005.

FEIBLEMAN, J. K. Theory of integrative levels. The British Journal for the Philosophy of Science, v. 5, n. 17, p. 54-66, 1954. Disponível em: <http://www.jstor. org/stable/685952>. Acesso em: 3 jul. 2010. 
FOSKETT, D. J. The theory of integrative levels and its relevance to the design of information systems. Aslib Proceedings, v. 30, n. 6, p. 202-208, 1978. Disponível em: <http://dx.doi.org/10.1108/eb050633>. Acesso em: 11 jan. 2011.

GAMBINI, R. Espelho de índio: a formação da alma brasileira. 2. ed. São Paulo: Axis Mundi/Terceiro Mundo Nome, 2000.

KUMAR, K. Theory of classification. 2nd ed. rev. New Delhi: Vikas Publishing House, 1981. 538 p.

LANGRIDGE, D. Classificação: abordagem para estudantes de Biblioteconomia. Tradução de Rosali P. Fernandez. Rio de Janeiro: Interciência, 1977. 126 p. Título original: Approach to classification for students of librarianship.

LARAIA, R. de B. Cultura: um conceito antropológico. Rio de Janeiro: Jorge Zahar. 2002.

LÉVI-STRAUSS, C. Antropologia estrutura dois. 4 ed. Rio de Janeiro: Tempo Brasileiro, 1993. 366 p.

LOUREIRO, J. de J. P. Cultura amazônica: uma poética do imaginário. São Paulo: Escrituras, 2001. 437 p. (originalmente tese de doutorado defendida na Universidade de Sorbonne, Paris, França).

MAUÉS, R. H. Uma outra “invenção” da Amazônia: religiões, histórias, identidades. Belém: Cejup, 1999. $283 \mathrm{p}$.

NOVO, H. A elaboração de taxonomia: princípios classificatórios para domínios interdisciplinares. 2007. 172 f. Dissertação (Mestrado em Ciência da Informação). Instituto de Artes e Comunicação Social, Universidade Federal Fluminense/ Instituto Brasileiro de Informação em Ciência e Tecnologia, Niterói, 2007.

NOVO, H. A taxonomia enquanto estrutura classificatória: uma aplicação em domínio de conhecimento interdisciplinar, Ponto de Acesso, v. 4, n. 2, p. 131156, set. 2010. Disponível em: <http://www.portalseer. ufba.br/index.php/revistaici/article/view/4103/3409 >. Acesso em: 22 dez. 2010.

NUNES, B. Um conceito de cultura. Belém: Conselho Estadual de Cultura, 2004. 24 p.

OLIVEIRA, M. O. E. de. Vocabulário terminológico cultural da Amazônia Paraense: com termos culturais da área de Abaetetuba, Belém, Santarém. Belém: EDUFPA, 2001, v.1, 159 p.
OLIVEIRA, M. O. E. de. Vocabulário terminológico cultural da Amazônia Paraense: com termos culturais da área de Castanhal. Belém: EDUFPA, 2005a, v.2, 167 p.

OLIVEIRA, M. O. E. de. Vocabulário terminológico cultural da Amazônia Paraense: com termos culturais da área de Bragança. Belém: EDUFPA, 2005b, v.3, 120 p.

RANGANATHAN, S.R. Prolegomena to library classification. Bombay: Asia Publishing House, 1967. $640 \mathrm{p}$.

RODRIGUES, A. L. C. Estrutura de classificação sob o enfoque da cultura amazônica. 2005. $125 \mathrm{f}$. Trabalho de Conclusão de Curso (Graduação em Biblioteconomia). Faculdade de Biblioteconomia, Universidade Federal do Pará, Belém, 2005.

RODRIGUES, A. L. C. O domínio cultura amazônica à luz da organização e representação da informação. 2011. 129 f. Dissertação (Mestrado em Ciência da Informação). Faculdade de Administração e Ciências Contábeis. Universidade Federal do Rio de Janeiro/ Instituto Brasileiro de Informação em Ciência e Tecnologia, Rio de Janeiro, 2011.

SARACEVIC, T. Information Science. Journal of the American Society for Information Science, v. 50, n. 12, p. 1051-1065, 1999. Disponível em: <http://dx.doi. org/10.1002/(SICI)1097-4571(1999)50:12<1051::AIDASI2>3.0.CO;2-Z>. Acesso em: 18 maio 2006.

SCHREINER, H. B. Considerações históricas acerca do valor das classificações bibliográficas. In: CONFERÊNCIA BRASILEIRA DE CLASSIFICAÇÃO BIBLIOGRÁFICA, 1. 1976, Rio de Janeiro. Anais... Rio de Janeiro: IBICT, 1979. p. 190-207.

SPITERI, L. F. The Classification Research Group and the Theory of Integrative Levels. The Katharine Sharp Review, n. 1, Summer, 1995.

TESAURO de Folclore e Cultura Popular Brasileira. Rio de Janeiro: Centro Nacional de Folclore e Cultura Popular, [2010].

UNIVERSAL Decimal Classification. [Amsterdam]: UDC Consortium, 2009. Disponível em: <http: http://www. udcc.org >. Acesso em: 15 nov. 2010.

VERÍSSIMO, J. Estudos amazônicos. Belém: Universidade Federal do Pará, 1970. 256 p.

WALDMAN, M. Tempo, modernidade e natureza. Caderno Prudentino de Geografia, n.16, p.24-73, 1995. Disponível em: <http://www.mw.pro.br/mw/ 
geog_tempo_modernidade_e_natureza.pdf $>$. Acesso em: 8 set. 2012 .

WILLIAMS, R. Cultura. 3 ed. Rio de Janeiro: Paz e Terra, 2008. 239 p.

WILSON, T. 'Information Science' and research methods. 2002, p.63-71. Disponível em: <http: informationr.net/tdw/publ/papers/sloval02.htm $>$. Acesso em: 10 dez. 2010.

The complexity of amazon culture and its repercussions on the organization and representation of information

\section{Abstract}

Introduction: It explores and analyzes the 'Amazon culture' domain in the context of organization and information representation. It presents concepts of culture in order to support reflections about the studied domain. Method: The supporting theoretical reference is focused on the Ranganathan's Faceted Classification Theory and on the Theory of Integrated Levels from the Classification Research Group, as theoretical-methodological basis to build a classificatory structure model. The selection of concepts took place based on the terms resulted from an oral research in three geographical cities of Amazon: Bragança, Castanhal and Marajo archipelago. Results: The analysis of etymological origins of the words indicated the influence of foreign culture from the European, African, Asiatic and American continents in the Amazon language. Conclusions: The analysis of those results showed the feasibility of developing a working methodology in order to outline a classification structure and a set of concepts to represent the 'Amazon culture' domain in its fundamental roots as a basis for the building of organizing systems of knowledge.

\section{Keywords}

Concepts. Domain analysis. Amazon culture. Knowledge organization. Information representation. Classification systems.

\section{Agradecimentos:}

A Deus por conceder tal oportunidade de estudo, a professora Rosali Fernandez pela orientação e amizade, pelas contribuições dos professores Maria Luiza Campos, Maria Odaisa e Jorge Biolchini, assim como todos os professores do IBICT. A CAPES pela bolsa concedida no mestrado. À família, Ana Lúcia, José Luiz, Allan e Geisa, Jean, Célia, Gabriela, Gabriel e minha esposa Natália e filhos Lucas e Leandro.

Recebido em 16 de agosto 2012

Aceito em 6 de setembro 2012

\section{Sobre 0 autor:}

\section{Anderson Luiz Cardoso Rodrigues}

Graduado em Biblioteconomia - Universidade Federal do Pará (UFPA), Mestre em Ciência da Informação Universidade Federal do Rio de Janeiro (UFRJ), em convênio com o Instituto Brasileiro de Informação em Ciência e Tecnologia (IBICT). Bibliotecário - Associação Brasileira de Engenharia Sanitária e Ambiental (ABES). andersonlcr@hotmail.com

Como citar este artigo:

RODRIGUES, A. L. C. A complexidade da cultura amazônica e seu reflexo para a organização e representação da informação. AtoZ, Curitiba, v. 1, n. 2, p. 10-25, jan./dez. 2012. Disponivel em: <http://www.atoz.ufpr.br>. Acesso em: 